10-16-2017

\title{
High Octane Gasoline Using Renewable Aromatic Hydrocarbons
}

\author{
Wayne Seames \\ University of North Dakota, wayne.seames@engr.und.edu \\ Malhar Khambete \\ Nahid Khatibi \\ Shelby Amsley-Benzie \\ Evguenii Kozliak
}

See next page for additional authors

How does access to this work benefit you? Let us know!

Follow this and additional works at: https://commons.und.edu/che-fac

Part of the Chemical Engineering Commons

\section{Recommended Citation}

Wayne Seames, Malhar Khambete, Nahid Khatibi, et al.. "High Octane Gasoline Using Renewable Aromatic Hydrocarbons" (2017). Chemical Engineering Faculty Publications. 6.

https://commons.und.edu/che-fac/6

This Article is brought to you for free and open access by the Department of Chemical Engineering at UND Scholarly Commons. It has been accepted for inclusion in Chemical Engineering Faculty Publications by an authorized administrator of UND Scholarly Commons. For more information, please contact und.commons@library.und.edu. 


\section{Authors}

Wayne Seames, Malhar Khambete, Nahid Khatibi, Shelby Amsley-Benzie, Evguenii Kozliak, Darrin Muggli, and Brian Tande

This article is available at UND Scholarly Commons: https://commons.und.edu/che-fac/6 


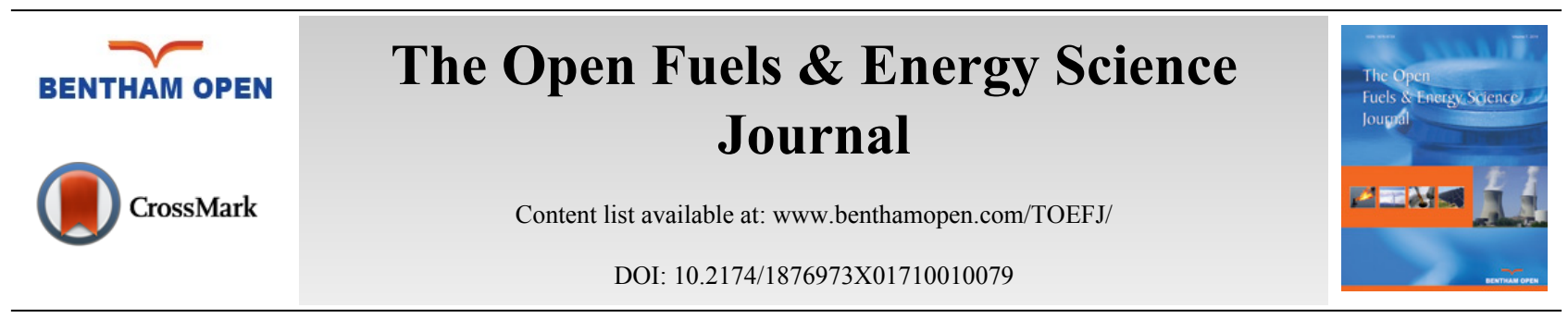

RESEARCH ARTICLE

High Octane Gasoline Using Renewable Aromatic Hydrocarbons

\author{
Wayne Seames ${ }^{1, *}$, Malhar Khambete ${ }^{1}$, Nahid Khatibi ${ }^{1}$, Shelby Amsley-Benzie ${ }^{1}$, Evguenii Kozliak ${ }^{2}$, \\ Darrin Muggli ${ }^{3}$ and Brian Tande ${ }^{1}$

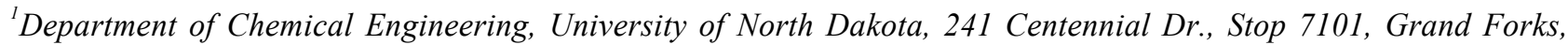 \\ ND58202-7101, USA \\ ${ }^{2}$ Department of Chemistry, University of North Dakota, 151 Cornell Street, Stop 9024, Grand Forks, ND58202-9024, \\ USA \\ ${ }^{3}$ Department of Engineering, Benedictine College, 1020 North $2^{\text {nd }}$ St., Atchison, KS 66002, USA
}

Received: July 11, 2017

Revised: September 07, 2017

Accepted: September 21, 2017

\title{
Abstract:
}

Background:

The replacement of leaded high octane aviation gasoline with an unleaded renewable alternative would decrease the emissions of lead and fossil-derived carbon into the atmosphere. Replacement has been limited by the requirement of a very high octane number in many existing general aviation aircraft engines.

\section{Method:}

Two separate process pathways were developed that generate an unleaded octane fuel with a motor octane number $>96$ from triglyceride oils (TGs), such as crop oils and algae oil. A series of experiments coupled with process simulations was used to verify the feasibility of both pathways and to provide preliminary laboratory scale data that could form the basis for further development towards a commercial technology. In the first pathway, TG oil is catalytically cracked to produce a high concentration of simple aromatic hydrocarbons. These aromatic hydrocarbons are then alkylated using propylene to form a mixture, which after purification acquires fuel properties compliant with those in the ASTM specification for 100 octane low lead aviation gasoline (100LL AvGas). In the second process pathway, the aromatic hydrocarbons are isolated after cracking using a sulfolane solvent extraction process to increase alkylation efficiency and fuel quality.

\section{Result:}

The results demonstrate that it is technically feasible to produce a replacement for 100LL AvGas using either pathway, and thus these strategies may be attractive candidates for commercialization.

Keywords: Catalytic cracking, Triglyceride oil, Renewable fuel, Aviation gasoline, Transportation fuel, Simulation modeling, Advanced biofuel.

\section{INTRODUCTION}

The sole U.S. transportation fuel that still uses additional tetraethyl lead (TEL) is 100 octane aviation gasoline (100LL AvGas), which is produced for reciprocating engines in certain types of aircraft. Approximately $45 \%$ of the U.S. ambient air lead inventory derives from the use of leaded AvGas [1]. In addition to environmental and health concerns, the limited availability of TEL has increased the price of the fuel, making renewable alternatives more economically attractive. To the best of our knowledge, there is now only one manufacturer, Innospec, in the world which produces TEL and there are only a very small number of refineries which produce 100LL AvGas. Leaded

\footnotetext{
" Address correspondence to this author at the Department of Chemical Engineering, University of North Dakota, 241 Centennial Dr., Stop 7101 , Grand Forks, ND 58202-7101, USA, Tel: +1-701-777-2958; Fax: +1-701-777-3773; E-Mail: wayne.seames@engr.und.edu
} 
AvGas requires (in the USA) completely separate transportation and storage facilities and the volume of AvGas production represents an extremely small portion (less than $1 \%$ ) of the gasoline marketplace [2].

To eliminate TEL from AvGas, octane enhancers must be developed that allow a fuel blend with a lean (motor) octane number on the order of 100 while still having energy density, freeze point, and flash point values that are similar to those of 100LL AvGas. An example of such a fuel is the alternative aviation gasoline developed by Swift Enterprises (Swiftjet). This fuel, produced from cellulosic biomass, contains over 80\% 1,3,5-trimethyl benzene with the balance being primarily 2-methyl butane [3]. Other researchers have looked at renewable options to extend the existing 100LL AvGas fuel supply, most notably with AGE85 being a certified lead-free replacement for AvGas [4].

It has been proposed that, similar to the Swift jet product, other alkylated aromatic hydrocarbons and/or cycloparaffins may be blended into a fuel mixture that could replace 100LL AvGas. In this study, two novel pathways were postulated that generate renewable alkylated aromatic hydrocarbons from a triglyceride (TG) oil feedstock that can be blended into a high octane AvGas. Lab-scale experimental work coupled with process simulations was then used to verify that each step of the proposed pathways was technically feasible. The primary objective being to identify one or two technically feasible pathways that could be developed and optimized into a commercially relevant process facility by future activities.

The biosynthesis of TGs is one of the most common energy storage strategies used in nature. They are most commonly synthesized by oilseed crops as well as certain strains of microalgae and bacteria. TGs are present in virtually every one of the earth's ecosystems, from deserts and tropics to arctic tundra. Abundance and the presence of hydrocarbon-like moieties make TGs an excellent starting material for the synthesis of a renewable high octane AvGas. In the present study, TG oil is fed to a catalytic reactor where the catalytic cracking of the TG oil can generate a mixture containing close to $70 \%$ of benzene, toluene, $o-, m$-, and $p$-xylene (BTX). The BTX in this mixture can be alkylated and/or hydrogenated to cycloparaffins to produce high octane AvGas Fig. (1). If a fuel with a more controlled composition or an even higher octane number is desired, the aromatic hydrocarbons can be extracted and purified prior to alkylation and then mixed to yield a more exact formulation (Fig. 2).

Significant previous work has been documented on the catalytic cracking of TG oils [5 - 14]. Most studies suggest that using a HZSM-5 zeolite catalyst produced the greatest yield of aromatic hydrocarbons during TG oil cracking. Key catalyst properties, such as the silica-alumina (Si/Al) ratio, calcination time and calcination temperature, affect HZSM-5 activity and product distribution. From these studies, the optimum reaction conditions for a desirable aromatics-rich liquid product are in the range of $50-60 \mathrm{Si} / \mathrm{Al}$ ratio, with a $500^{\circ} \mathrm{C}$ calcination temperature and a $6 \mathrm{~h}$ calcination time.

$\begin{array}{lllc}\text { Catalytic } & \text { Crackate } & \text { Alkylation } & \text { Product } \\ \text { Cracking } & \text { Separation } & \text { Reactions } & \text { Purification }\end{array}$

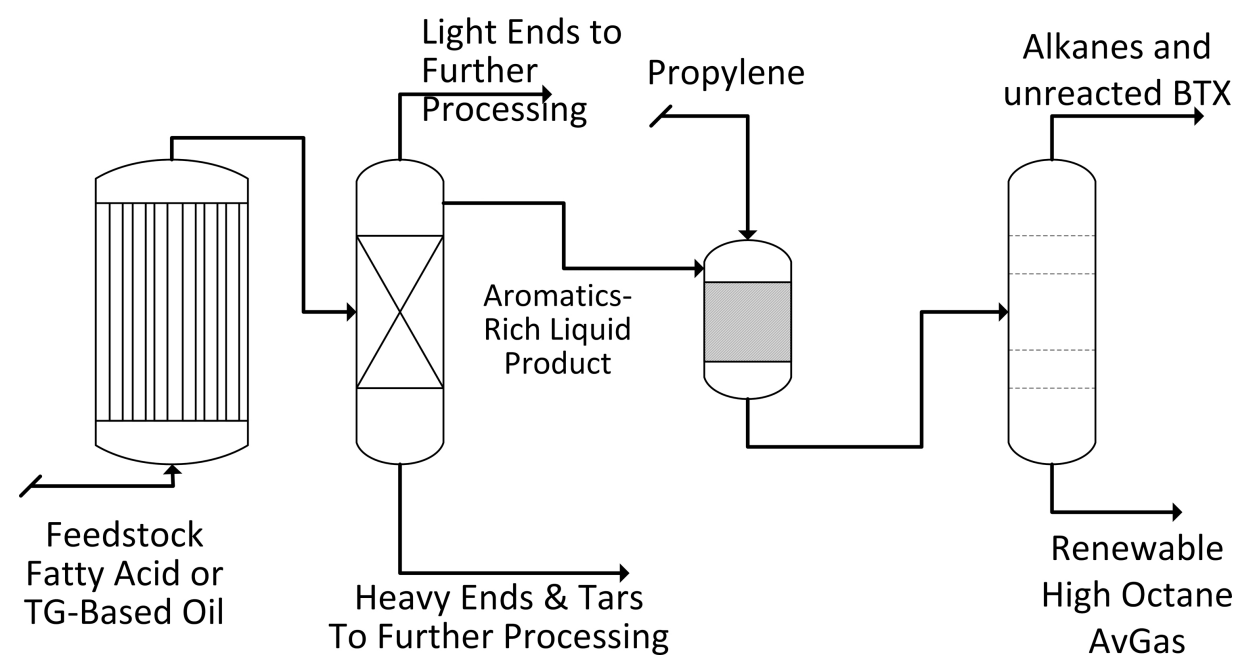

Fig. (1). A process scheme to generate a mixed stream of high octane aromatic compounds for use as an aviation gasoline.

Once the cracking product is generated, it can be separated from lighter (non-condensable against room temperature 
water) and heavier materials leaving an aromatics-rich liquid product (ALP). The primary aromatic hydrocarbons produced by catalytic cracking with HZSM-5 are simple BTX (benzene, toluene, xylenes) compounds. These simple aromatic hydrocarbons must be converted into higher aromatic homologues to make a suitable replacement for $100 \mathrm{LL}$ AvGas. This can be accomplished by the alkylation of benzene, toluene, and xylenes using propylene to cumene, cymene and isopropyl xylenes, respectively. Previous research has shown that $\beta$-zeolite and HZSM-5 catalysts facilitate these alkylation reactions [15 - 20]. In a comparative study by Perego et al. $\beta$-zeolite was shown to be the only commercially available zeolite that had a relatively large propylene conversion [21]. As a result, $\beta$-zeolite was used in all alkylation reaction experiments performed.

For the alkylation step, there are two process options available Figs. (1 and 2): a) direct alkylation of the ALP mixture and b) extraction/purification of the aromatic hydrocarbons from the ALP followed by alkylation of the individual aromatic hydrocarbons. Both of these options were explored in the present work.

The separation of aromatic and aliphatic hydrocarbon mixtures is challenging due to the overlapping range of boiling points of the selected compounds. Several combinations of aromatic hydrocarbons and alkanes also form azeotropes. Processes that have been studied for the separation of aromatic hydrocarbons from aliphatic hydrocarbon mixtures include: liquid extraction, suitable for the range of 20-65 wt.\% aromatic content [22], extractive distillation for the range of $65-90 \mathrm{wt} . \%$ aromatic hydrocarbons [23], and azeotropic distillation for high aromatic content, $>90 \mathrm{wt} . \%$ [24]. The most common solvent used for the extraction of BTX is sulfolane (tetrahydrothiophene-1,1-dioxide) [22, 25, 26]. This solvent was used in the present work. Alternative solvents include: ethylene carbonate [27], $n$ formylmorpholine (NFM) [28], glycols [27, 29], and ionic liquids [24, 26, 30, 31].

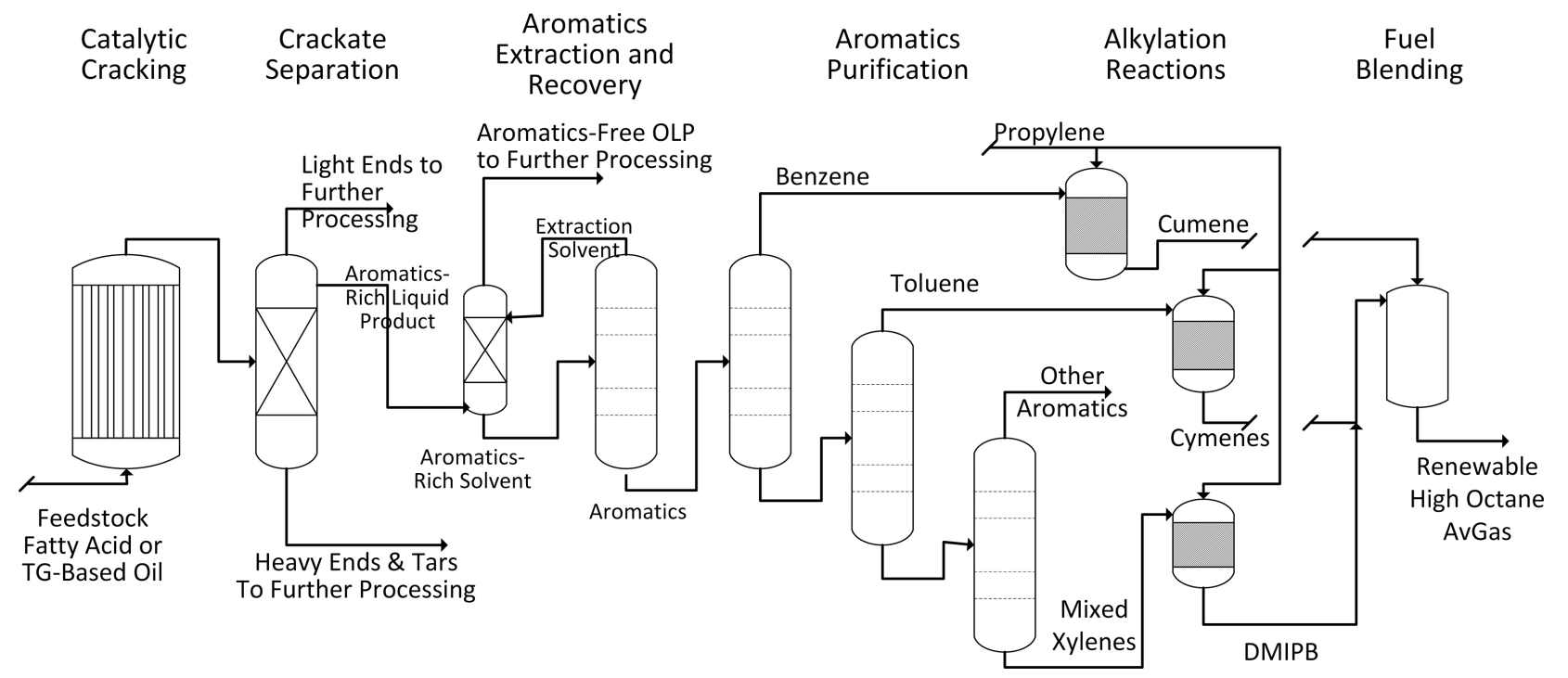

Fig. (2). A process scheme to generate a more controlled high octane aromatics product for use as an aviation gasoline.

\section{MATERIALS AND METHODS}

\subsection{Materials}

Degummed soybean oil was obtained from Northwood Mills (Northwood, ND, USA). A typical fatty acid profile for this oil is provided in supplemental Table (S1). The cracking catalyst was commercial ZSM-5 (CVV5524G, Zeolyst International, Conshohocken, $\mathrm{PA}, \mathrm{USA}$ ) in $\mathrm{NH}_{4}$ form, having a $\mathrm{Si} / \mathrm{Al}$ ratio of 50 and a surface area of $425 \mathrm{~m}^{2} / \mathrm{g}$. The catalyst was calcined as described in section 2.2.1, below. The alkylation catalyst was beta zeolite (CP814E, Zeolyst International, Conshohocken, PA, USA) having an $\mathrm{Si} / \mathrm{Al}$ ratio of 25 and an $\mathrm{Na}_{2} \mathrm{O}$ concentration of $0.05 \mathrm{wt} \%$. The surface area of the catalyst was $680 \mathrm{~m}^{2} / \mathrm{g}$. Sulfolane with a purity of $97 \mathrm{wt} \%$ was used to extract the BTX out of the catalytically cracked soybean oil. Benzene, toluene, $o-, m$-, and $p$-xylene were obtained from Sigma-Aldrich (St. Louis, MO, USA). The reaction gases, propylene, hydrogen and nitrogen at 99.9\% purity, were obtained from Praxair, Inc. (Danbury, CT, USA). 
Table S1. Typical soybean oil fatty acid profile.

\begin{tabular}{|l|c|}
\hline \multicolumn{1}{|c|}{ Fatty Acid Moiety } & Composition (mol \%) \\
\hline Palmitic (16:0) & 11 \\
\hline Stearic (18:0) & 4 \\
\hline Oleic (18:1) & 26 \\
\hline Linoleic (18:2) & 50 \\
\hline Linolenic (18:3) & 8 \\
\hline Other & 1 \\
\hline
\end{tabular}

Gases used for gas chromatography (GC) analysis were obtained from Praxair (Praxair, Inc., Danbury, CT, USA) at $99.999 \%$ or greater purity. For detailed quantitative characterization of samples by gas chromatography, a number of standards were used. For identification, the following standard mixtures were purchased from Supelco (Bellefonte, PA, USA): isoparaffin-, aromatic-, naphthene-, and olefin-alphagaz PIANO [32]; naphtha, reformate, and alkylate qualitative reference standards; petroleum crude qualitative and quantitative standards [33].

For quantification of the cracking products, individual chromatographic standards of analytical grade were used representing the complete series of unbranched alkanes $\left(\mathrm{C}_{5}-\mathrm{C}_{18}\right)$, selected alkenes $\left(\mathrm{C}_{6}, \mathrm{C}_{9}, \mathrm{C}_{14}, \mathrm{C}_{18}\right)$, and aromatic hydrocarbons (benzene, toluene, $o$-xylene, $m$-xylene, $p$-xylene 1,2,4-trimethylbenzene, indane, naphthalene). Various solvents were purchased from Fischer Scientific (Waltham, MA, USA): acetonitrile (HPLC grade), methylene chloride (GC grade). $N$-methyl- $N$-trimethylsilyltrifluoracetamide (MSTFA) was used as a derivatization agent for GC analysis of carboxylic acids and alcohols (Supelco, Bellefonte, PA, USA).

Internal standard calibrations were performed with a mixture of benzene- $\mathrm{d}_{6}\left(102.1 \mathrm{mg} \cdot \mathrm{mL}^{-1}\right), 2$-chlorotoluene $(100.1$ $\left.\mathrm{mg} \cdot \mathrm{mL}^{-1}\right)$ and $o$-terphenyl $\left(49.8 \mathrm{mg} \cdot \mathrm{mL}^{-1}\right)$ in methylene chloride. All were purchased from Sigma-Aldrich (St. Louis, MO, USA). These standards were selected because they are representative of the classes of compounds of interest, will not be produced during the reactions, and provide signals that are unlikely to interfere with the product compound outputs.

For the quantification of acids and alcohols in derivatized samples, a calibration mixture $\left(0.10-75.0 \mathrm{mg} \cdot \mathrm{mL}^{-1}\right) \mathrm{was}$ used consisting of several representative carboxylic acids (acetic, propionic, butyric, hexanoic, octanoic, decanoic, and palmitic), $n$-butanol, $n$-hexanol, 1,3-propanediol, glycerol, and $n$-decanol. For identification, a standard mixture consisting of $\mathrm{C}_{1}-\mathrm{C}_{16}$ carboxylic acids and $\mathrm{C}_{1}-\mathrm{C}_{10}$ alcohols was employed. Geraniol (Aldrich, St. Louis, MO, USA) and $o$-terphenyl were used as recovery $\left(10 \mathrm{mg} \cdot \mathrm{mL}^{-1}\right.$ in acetonitrile $)$ and internal standards $\left(50.0 \mathrm{mg} \cdot \mathrm{mL}^{-1}\right.$ in $\mathrm{methylene}$ chloride), respectively.

\subsection{Catalyst Pretreatment}

Both the cracking and alkylation catalysts were activated by calcination. The cracking catalyst was heated at $600^{\circ} \mathrm{C}$ while the alkylation catalyst was heated at $450^{\circ} \mathrm{C}$, both for six hours in an oven. The catalyst was allowed to cool down to room temperature in a nitrogen atmosphere. The calcinated catalyst was then transferred to an air tight container until use.

\subsection{Cracking Reactions}

All cracking experiments were conducted in a $500 \mathrm{~mL}$ volume, high temperature, high pressure batch reactor (Parr 4575 series HP/HT reactor, Moline, IL, USA) as shown in Fig. (3). The specified amount of activated catalyst added to the reaction vessel was based on the oil/catalyst weight ratio in the design of experiments for the weight of $200 \mathrm{~mL}$ of soybean oil. The reactor was purged with nitrogen to insure an inert environment.

Upon completion, the liquid and residual contents were measured to obtain the overall yield data. No tar was found in the liquid after collecting the product on the $500 \mathrm{~mL}$ batch reactor setup as all of the highly viscous material solidified in the reactor upon cooling and was mixed with the catalyst to form a residual matter. All of the residual matter was carefully collected from the agitator blades, cooling coil, thermowell, other internal parts of the reactor and the reactor vessel. The difference in the weight of the catalyst before and after the reaction was measured and assumed to be coke. While it is possible that minor levels of absorbed reagents and other material could have also been present, characterizing all of these as coke was deemed adequate for the proof of concept level study being conducted.

The concentration of BTX in the ALP was increased by selectively separating out the distillate fractions that were 
most likely to contain the selected aromatic hydrocarbons based on the boiling points of each component. Batch distillations were performed at atmospheric pressure in a quartz round bottom flask equipped with a distillation column and a water cooled condenser. Distillation temperatures ranged from 80 to $144^{\circ} \mathrm{C}$.

For the sulfolane extraction experiments, soybean oil was cracked at the near optimum conditions found in the initial cracking optimization study in the same reactor. The ALP was generated by batch distillation at $135^{\circ} \mathrm{C}$.

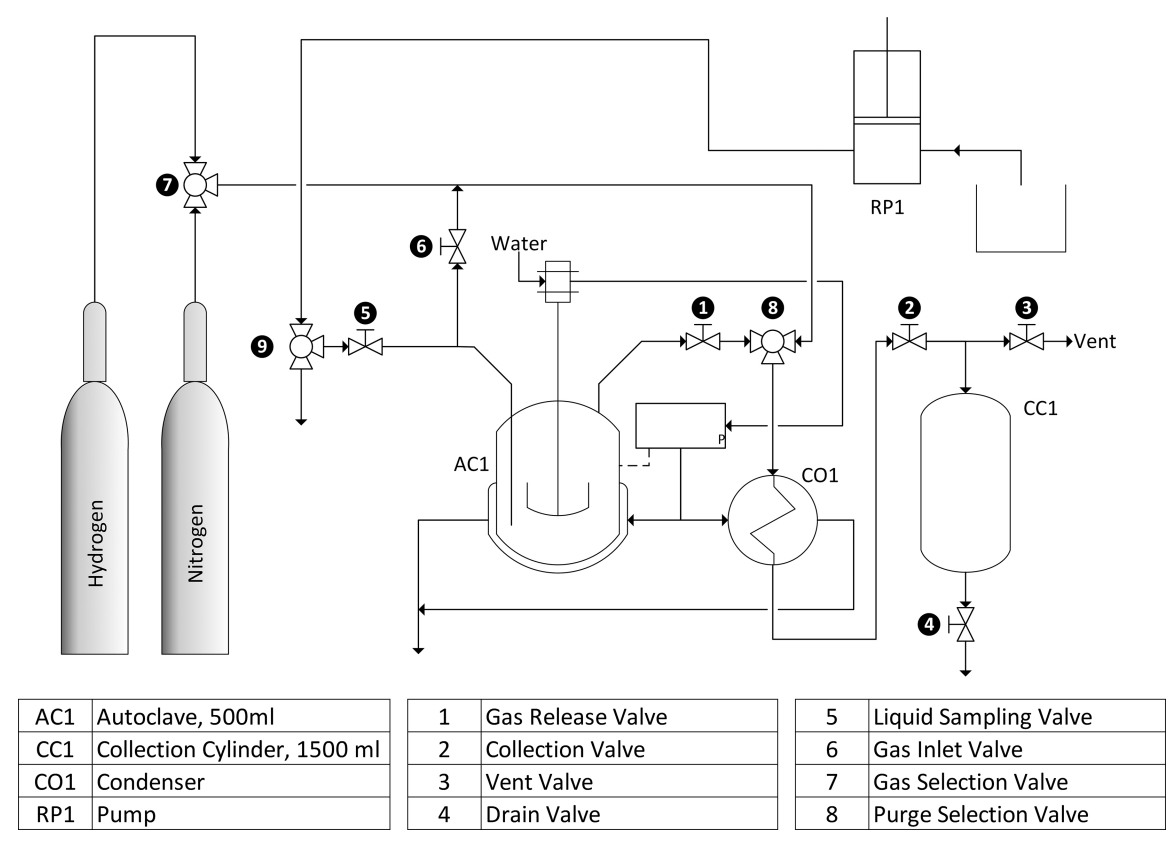

Fig. (3). Cracking reactor system.

\subsection{Sulfolane Extraction Experiments}

For the process option shown in Fig. (2), sulfolane was used to extract the BTX from the ALP. Because the ALP is a unique process mixture, simple extraction experiments were required to determine the partitioning coefficients of BTX into sulfolane from the ALP. The sulfolane extraction experimental setup replicated a mixer/settler arrangement. All experiments were conducted in $20 \mathrm{~mL}$ volume test tubes and at atmospheric pressure. A sonicator (Fisher Scientific model FS60H, Waltham, MA, USA) was used as the mixer and a centrifuge (Centrific Model 228, Fisher Scientific, Waltham, MA, USA) was used as the settler.

Five grams of ALP were added to each of six test tubes. The proper amount of sulfolane was added to each test tube for the three solvent- to-solute ratios and mixed in the sonicator for 10 minutes. The sonicator internal heater was used to maintain the extraction temperature at the desired condition $\left(30,50\right.$, or $\left.70^{\circ} \mathrm{C}\right)$. After mixing, the test tubes were placed in the centrifuge and spun for four minutes. The two phases, ALP rich solvent (aqueous) and ALP lean solvent (organic), were collected, weighed, and stored for analysis.

The next step in this process option Fig. (2) is to separate the BTX from the sulfolane and purify the BTX fractions that will be used in the alkylation reactions. The recovery of BTX from sulfolane and the subsequent separation of the BTX product mixture into pure components are well developed and used in commercial petroleum-based aromatics production processes. Thus, it was deemed sufficient to simulate these steps using the ChemCad process simulation system as described in section 2.6 , below.

\subsection{Alkylation Reactions}

\subsubsection{Preliminary Experiments}

Preliminary alkylation experiments were conducted to study the feasibility of the reactions based on information from literature. These experiments were conducted in a $500 \mathrm{~mL}$ Parr (Moline, IL, USA) bench-scale autoclave reactor system similar to that described above for the catalytic cracking work. The actual system is shown in Fig. (S1). In these experiments, nitrogen was used to pressurize the autoclave to enable the propylene to liquefy and thus be in the same 
phase as the aromatic hydrocarbons, which facilitates adsorption onto the catalyst. At fixed time intervals, samples were drawn using a dip tube to study the progress of a reaction. At the end of the reaction the slurry of the remaining product and catalyst was removed from the vessel. The spent catalyst was separated in a centrifuge and the extractant collected for analysis by GC to determine the change in composition of reactants and products.

Several experiments were carried out to assess the progress of the reaction and also to determine the selectivity of the catalyst being studied. A BTX blend was used that matched the ALP concentration obtained from the experimental cracking reactions described above. Propylene was used as the alkylation chemical because it is an abundant by-product from the cracking of soybean oil [34] and thus would be available internally in a commercial facility.

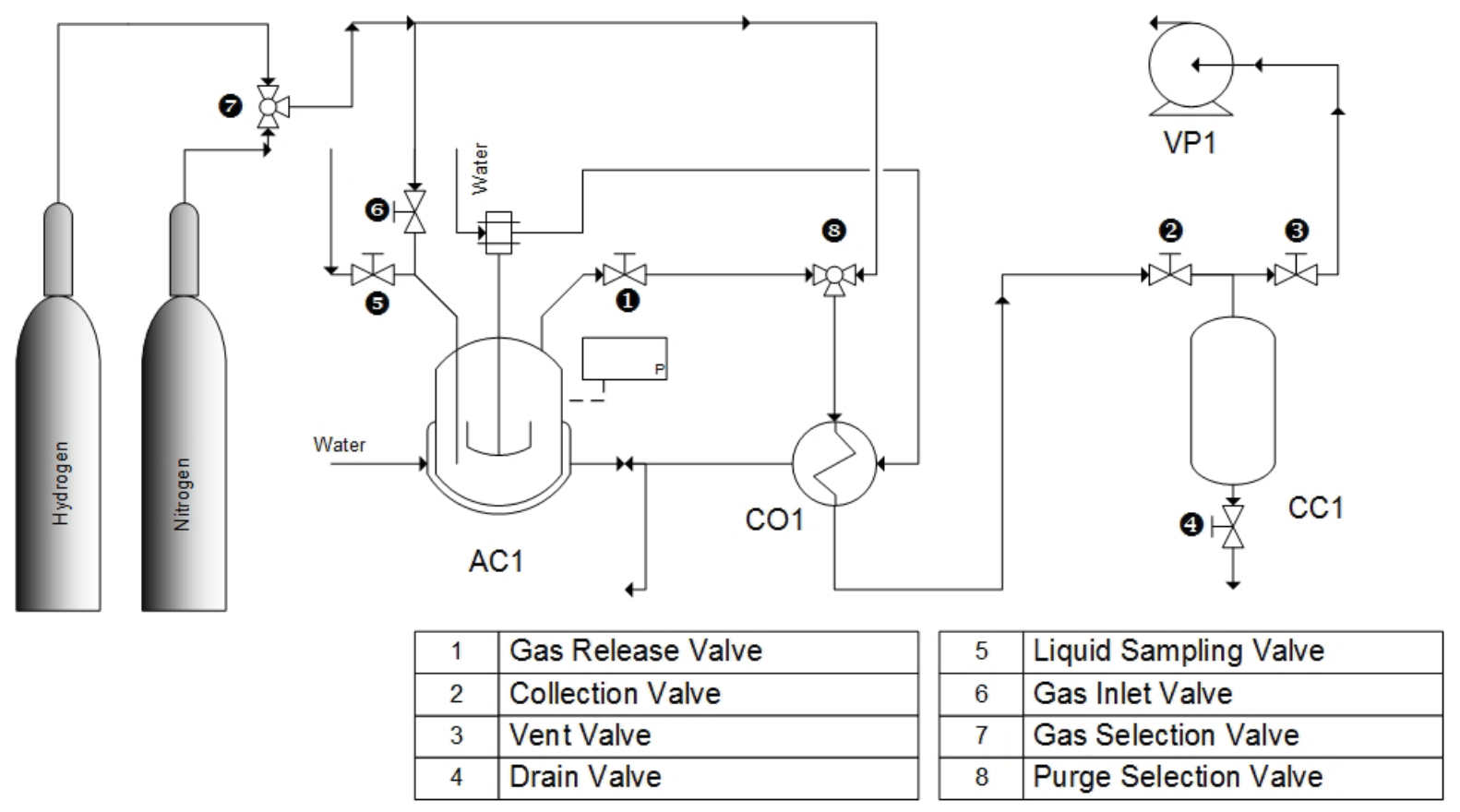

Fig. (S1). Autoclave reactor system.

\subsubsection{Model Compound Alkylation}

Once the feasibility of these reactions was established, model compounds were alkylated to measure the yield and octane number of the products. These experiments also provided the data needed to evaluate the process alternative described in Fig. (2). These reactions were carried out in a 5.5 L Parr (Moline, IL, USA) high temperature, high pressure batch reactor. The overall configuration of the $5.5 \mathrm{~L}$ Parr autoclave was similar to the $500 \mathrm{~mL}$ Parr autoclave that was used in the alkylation and cracking experiments described above in Fig. (3) with the absence of a vacuum pump being the only difference.

In these studies, model BTX compounds were alkylated with propylene separately and then in a blend whose proportions correspond to the ALP generated by the cracking/ concentration scheme described in section 2.3. Reaction progress was studied by varying the reaction time for $5,10,30$, and 60 minutes.

\subsection{Analytical Methods}

The octane number was measured on a Zeltex Inc. (Hagerstown, Maryland, USA) octane and fuel analyzer (ZX-101XL) having a detection limit of 99.5 ON. Values above this point were estimated using literature values, as described in section 2.7, below. Prior to each test, the accuracy of the instrument was confirmed by calibrating the instrument to octane numbers of compounds within its detectable range, namely hexane and cyclohexane.

GC quantification was performed following the method developed by Kubatova and co-workers [34 - 37 ]. This method uses a GC-FID/MS (Agilent 7890N GC, 5975C MS, Santa Clara, CA, USA) equipped with an autosampler (7386B series) and a split/splitless injector. Separations were accomplished using a $100 \mathrm{~m}$ long DB-1MS capillary column with a $0.25 \mathrm{~mm}$ internal diameter and $0.25 \mu \mathrm{m}$ film thickness and a constant helium flow rate. The MS and FID data were simultaneously acquired by employing a two-way splitter with a helium makeup gas with a split flow ratio of 
1:2 (MS:FID). The MS data (total ion chromatogram, TIC) was acquired in the full scan mode using electron ionization. The standards used are listed in section 2.1 and products were identified based on the NIST MS library.

Key fuel physical properties were determined using commercial (ASTM) standard methods [38]. Standardized test methods were used to determine the following critical physical properties of the refined fuel: density [39], total acid number [40], freeze point [41], flash point [42], and heat of combustion [43]. Numerous other specification tests are required to fully certify fuels, such as distillation analysis [44], and the fraction of olefins in the fuel, and the fraction of aromatic hydrocarbons in the fuel [45]. However, these were not performed in the present work as the suite of tests that were performed was considered adequate to assess the potential of the proposed process pathways to generate a viable aviation gasoline fuel product

\subsection{Process Simulation and Parameter Estimation}

\subsubsection{Extracted BTX Purification Modeling}

A model system was built to determine the estimated recovery of BTX and the purity of the regenerated solvent following the process pathway shown in Fig. (2) using the ChemCAD ${ }^{\circ}$ (Houston, TX, USA) version 6.4.1 process simulator. The following simplifying assumptions were made:

1. Aromatic hydrocarbons heavier than xylenes were all assumed to be one compound - cumene. This was based on the analysis of this fraction from selected experiments where over $80 \%$ of this fraction was quantified as cumene.

2. Only BTX was assumed to be extracted by the sulfolane, with all other compounds staying in the aromatics-lean extraction product liquid.

3. The entire amount of sulfolane in the LLE was assumed to be in the rich solvent stream (no sulfolane in aromatics-lean extraction product liquid).

The average composition of the rich solvent stream determined from the sulfolane extraction experiments was used as the feed composition to the solvent recovery system. The feed was assumed to enter the recovery column at $100^{\circ} \mathrm{C}$ and 1 atm pressure (Fig. 2).

Different thermodynamic packages are used in process simulators for aromatics/aliphatic mixtures and sulfolane. Among the various thermodynamic models, the nonrandom two-liquid model (NRTL) and the UNIversalQUAsiChemical equation (UNIQUAC) model are universal methods for estimating TG oil compound properties. Studies show that both models can be used to correlate the experimental data [46 - 48].

Lee et al. [49] measured the VLE for a system containing sulfolane + octane + aromatics (benzene, toluene, and pxylene) to improve the correlation and thus the prediction of liquid-liquid equilibrium. They concluded that the NRTL model provided the best fit of the experimental data. Lee et al. in another study [50] showed that for the calculated values for liquid-liquid equilibrium data for the systems -- sulfolane + octane + benzene, sulfolane + octane + toluene and sulfolane + octane $+p$-xylene -- the NRTL model provided a more accurate estimation than the UNIQUAC model. Ashour et al. [51] showed that to model liquid-liquid equilibrium data for four ternary systems comprising cyclohexane + (benzene, toluene, ethyl benzene, or cumene) + sulfolane measured at 303.15K and at atmospheric pressure, both UNIFAC and NRTL models represented the experimental data with sufficient accuracy. Therefore NRTL was used in this study.

\subsubsection{Octane Number}

Theoretical calculations were performed to predict the octane number of different blends produced by the alkylation of BTX with propylene and methanol. For calculating the theoretical octane numbers, flash points and heats of combustion of the blends, weighted averages of the individual properties were used. For example, in a mixture of cumene (14\%), cymene $(40 \%)$ and TMB (46\%), the octane number of the final mixture was calculated by taking a weighted average from each components MON octane value:

$$
\mathrm{ON}=((0.14 * 99.3)+(0.40 * 96.9)+(0.46 * 110))=103.24
$$

Calculations for the octane number, flash point, and heat of combustion were based on the values for those compounds found in the API Technical Data Book [52]. 
Properties for various blends of cumene (isopropyl benzene), cymenes (1-methyl-2-isopropylbenzene, 1-methyl-3isopropylbenzene, and 1-methyl-4-isopropylbenzene), and DMIPB (dimethlyisopropyl benzene) were calculated by varying the amount of each at four different levels. As no experiments were performed with methanol alkylation, theoretical blends from methanol alkylation were constructed to evaluate this option for future development work. These calculations were used to predict the blends that would yield the highest octane number, flash point, and heat of combustion.

\section{RESULTS AND DISCUSSION}

\subsection{Catalytic Cracking Reactions}

Catalytic cracking of TG oils using HZSM-5 to produce an aromatics-rich liquid product has been well studied [5 14]. Therefore, complete optimization of this process step was not considered to be necessary. Instead, a series of 16 experiments were performed using the DOE scheme specified in (Table 1) in order to identify reaction conditions that would be productive for ALP generation using the available experimental facilities. For example, the cracking reaction temperature range was chosen based on results in previous work [53]. Five factors were varied in a two-level half fractional factorial design. The order of experiments was randomized in order to mitigate the effect of any potential background variables. Soybean oil was chosen since it is the most common crop oil in the world, is readily available, and has been extensively studied in our previous work on TG cracking [35, 53 - 55]. However, the overall conclusions reached should be applicable to a wide variety of TG oil feedstocks.

Table 1. Design of experiments for catalytic cracking of soybean oil.

\begin{tabular}{|c|c|c|c|c|c|}
\hline $\begin{array}{c}\text { Run } \\
\text { Order }\end{array}$ & Reaction Temp. ${ }^{\circ} \mathbf{C}$ & Reaction Time min & $\begin{array}{c}\text { Weight of Catalyst } \\
\mathbf{g}\end{array}$ & Hydrogen \% & Gas Pressure MPa \\
\hline 1 & 430 & 20 & 19.1 & 0 & 0.1 \\
\hline 2 & 430 & 20 & 38.2 & 100 & 0.1 \\
\hline 3 & 430 & 60 & 19.1 & 0 & 1.4 \\
\hline 4 & 410 & 60 & 19.1 & 0 & 0.1 \\
\hline 5 & 410 & 20 & 19.1 & 100 & 1.4 \\
\hline 6 & 430 & 60 & 38.2 & 100 & 1.4 \\
\hline 7 & 410 & 60 & 19.1 & 0 & 1.4 \\
\hline 8 & 410 & 60 & 38.2 & 0 & 1.4 \\
\hline 9 & 430 & 20 & 38.2 & 0 & 1.4 \\
\hline 10 & 430 & 60 & 38.2 & 0 & 0.1 \\
\hline 11 & 410 & 20 & 38.2 & 100 & 0.1 \\
\hline 12 & 410 & 20 & 19.2 & 100 & 0.1 \\
\hline 13 & 430 & 60 & 19.2 & 100 & 0.1 \\
\hline 14 & 430 & 20 & 19.2 & 100 & 1.4 \\
\hline 15 & 410 & 60 & 38.2 & 100 & 0.1 \\
\hline 16 & 410 & 20 & 38.2 & & 1.4 \\
\hline
\end{tabular}

A summary of the composition of the ALP generated at each reaction condition is shown in Table (2). It should be noted that these results exclude quantification of short chain fatty acids which have been found in previous work to be decarboxylated during soybean oil HZSM-5 catalytic cracking to concentrations on the order of $<0.05 \mathrm{wt} \%$ of the ALP [53].

The maximum conversion of TG oil to aromatic hydrocarbons was around $35 \mathrm{wt} \%$ based on the inlet mass of TG oil Table (2), Run 8). Note that this is a more rigorous measure than is often seen in the literature where the fraction of the GC elutable and quantified compounds is used, which would be a much higher value. We use fraction of inlet oil mass as it is a more accurate measure of conversion efficiency. This value was obtained at the higher cracking temperature $\left(430^{\circ} \mathrm{C}\right)$, atmospheric pressure, longer residence time $(60 \mathrm{~min})$, higher catalyst-to-reactant ratio, and in the absence of hydrogen. Runs $10,11,15$, and 16 yielded similar results.

Within the bounds of the DOE, there was a clear positive effect leading to higher aromatics concentrations when the quantity of catalyst used (representing the catalyst-to-feedstock ratio) was increased. Reaction temperature, within the narrow range studied, had little effect. While we had postulated that hydrogen addition might inhibit aromatics formation, the results suggest that this is not the case. 
Table 2. Composition results for the ALP excluding fatty acids (PAHs $=$ polycyclic aromatic hydrocarbons, $\mathbf{w} / \mathbf{w} \%=\mathrm{mass}$ of compounds in the category per total GC elutable mass in \%).

\begin{tabular}{|c|c|c|c|c|c|}
\hline Run & Alkanes & Cycloalkanes & Alkenes & Aromatics & PAHs \\
\hline Order & $\mathbf{w} / \mathbf{w} \%$ & $\mathbf{w} / \mathbf{w} \%$ & $\mathbf{w} / \mathbf{w} \mathbf{0}$ & $\mathbf{w} / \mathbf{w} \mathbf{0}$ & $\mathbf{w} / \mathbf{w} \mathbf{0}$ \\
\hline 1 & 4.4 & 0.17 & 0.31 & 15.1 & 1.8 \\
\hline 2 & 1.1 & 0.03 & 0.18 & 25.4 & 5.0 \\
\hline 3 & 3.2 & 0.13 & 0.30 & 17.8 & 3.4 \\
\hline 4 & 4.5 & 0.16 & 0.50 & 16.0 & 1.5 \\
\hline 5 & 2.8 & 0.10 & 0.42 & 34.7 & 1.2 \\
\hline 6 & 2.0 & 0.09 & 0.29 & 21.4 & 8.9 \\
\hline 7 & 6.1 & 0.17 & 0.55 & 33.4 & 2.0 \\
\hline 8 & 1.5 & 0.07 & 0.26 & 28.4 & 8.1 \\
\hline 9 & 2.6 & 0.08 & 0.12 & 35.4 & 4.4 \\
\hline 10 & 1.7 & 0.08 & 0.12 & 29.4 & 7.0 \\
\hline 11 & 1.2 & 0.06 & 0.15 & 13.7 & 7.3 \\
\hline 12 & 4.9 & 0.15 & 0.60 & 21.3 & 1.4 \\
\hline 13 & 3.5 & 0.18 & 0.37 & 18.2 & 4.1 \\
\hline 14 & 4.9 & 0.17 & 0.47 & 31.8 & 2.1 \\
\hline 15 & 1.2 & 0.04 & 0.31 & 33.4 & 9.7 \\
\hline 16 & 1.2 & 0.04 & 0.27 & & 9.0 \\
\hline
\end{tabular}

\subsection{Alkylation Reactions}

Several experiments were carried out to understand the progress of the reaction and also to determine the selectivity of the catalyst being studied. Table (3) provides a summary of the alkylation reactions carried out along with the products that were identified. Please note that these proof-of-feasibility experiments provide insight into the reasonableness of the two potential process pathways and do not represent fully optimized experimental reaction data.

For toluene the most common product detected was 1-methyl-x-(1-isopropyl) benzene. Here, the " $x$ " indicates the changing location on the benzene ring. This number can be 2, 3 or 4. 1, 2-dimethyl-x-isopropyl-benzene was the product of alkylation of $o$-xylene with propylene. The " $\mathrm{x}$ " here takes the position 3 or 4 . Similarly for $m$ - and $p$-xylene, the products were 2,4-dimethyl-x-(1-isopropyl) benzene and 1,4-dimethyl-x-(1-isopropyl) benzene with the positions for " $\mathrm{x}$ " as 2, 4 or 5 and 2 and 3, respectively. It should be noted that in all of these experiments, the aromatic stream was in stoichiometric excess which allowed us to study the selectivity of propylene for alkylation.

Table 3. The alkylation of aromatics with propylene.

\begin{tabular}{|c|c|c|c|c|}
\hline $\begin{array}{c}\text { Reaction Time } \\
\text { (min) }\end{array}$ & Aromatic & $\begin{array}{c}\text { Feed } \\
\text { Aromatic/ } \\
\text { Propylene molar } \\
\text { ratio }\end{array}$ & $\begin{array}{c}\text { Propylene } \\
\text { Conversion } \\
\mathbf{\%}\end{array}$ & Products (Selectivity) \\
\hline 60 & ALP & 5 & 50 & cumene, cymene, isopropyl xylenes \\
\hline 60 & ALP & 20 & 50 & cumene (20\%), cymene(40\%), isopropyl xylenes(40\%) \\
\hline 60 & ALP & 10 & 100 & cumene (20\%), cymene(40\%), isopropyl xylenes(40\%) \\
\hline 30 & Benzene & 50 & 20 & 1-(isopropyl)benzene \\
\hline 60 & Benzene & 10 & 30 & 1-(isopropyl)benzene \\
\hline 60 & Benzene & 50 & 40 & 1-(isopropyl)benzene \\
\hline 60 & Benzene & 1 & 70 & 1-(isopropyl)benzene \\
\hline 60 & Benzene & 15 & 100 & 1-(isopropyl)benzene \\
\hline 5 & Toluene & 1 & 50 & 1-methyl-x-(1-isopropyl)benzene (3 isomers) \\
\hline 10 & Toluene & 20 & 100 & 1-methyl-x-(1-isopropyl)benzene (3 isomers) \\
\hline 30 & Toluene & 10 & 100 & 1-methyl-x-(1-isopropyl)benzenene (3 isomers) \\
\hline 60 & Toluene & 80 & 100 & 1-methyl-x-(1-isopropyl)benzene (3 isomers) \\
\hline 60 & Toluene & 10 & 100 & 2,4-dimethyl-x-(1-isopropyl)benzene \\
\hline 5 & m-Xylene & 70 & 10 & 2,4-dimethyl-x-(1-isopropyl)benzene \\
\hline 10 & m-Xylene & 10 & 30 & 2,4-dimethyl-x-(1-isopropyl)benzene \\
\hline 30 & m-xylene & 10 & 50 & \\
\hline
\end{tabular}




\begin{tabular}{|c|c|c|c|c|}
\hline $\begin{array}{l}\text { Reaction Time } \\
\text { (min) }\end{array}$ & Aromatic & \begin{tabular}{|c|} 
Feed \\
Aromatic/ \\
Propylene molar \\
ratio
\end{tabular} & $\begin{array}{c}\text { Propylene } \\
\text { Conversion } \\
\%\end{array}$ & Products (Selectivity) \\
\hline 60 & m-Xylene & 10 & 70 & 2,4-dimethyl-x-(1-isopropyl)benzene \\
\hline 60 & m-Xylene & 10 & 80 & 2,4-dimethyl-x-(1-isopropyl)benzene \\
\hline 60 & p-Xylene & 10 & 100 & 1,4-dimethyl-x-(1-isopropyl)benzene \\
\hline 60 & o-Xylene & 70 & 100 & 1,2-dimethyl-x-isopropyl-benzene \\
\hline \multicolumn{4}{|c|}{ Reaction temperature $=150^{\circ} \mathrm{C}$, Pressure $=3.4 \mathrm{MPa}$} & Cumene is 1-(isopropyl)benzene \\
\hline \multicolumn{4}{|c|}{$\begin{array}{l}\text { ALP is comprised of model BTX compounds blended to match the experimental } \\
\text { results from the cracking/purification steps }\end{array}$} & $\begin{array}{l}\text { Cymenes are 1-methyl-x-(1-isopropyl)benzene and their } \\
\text { isomers }\end{array}$ \\
\hline & & & & Isopropyl xylenes are products from Xylenes \\
\hline
\end{tabular}

The first three experiments support process pathway 1 Fig. (1). The experiments were highly selective for the target alkylated aromatic compounds and yielded reasonable propylene conversion. A 1:2:2 ratio of cumene, cymene, and isopropyl xylenes were obtained from the model ALP mixture corresponding to the BTX ratio measured from the Table (1), Run 8 experiments. These compounds were used in the fuel formulation blends and calculations described in section 3.5, below. The remaining experiments support process pathway 2 (Fig. 2). Again, the results show high selectivity to the target alkylated aromatic hydrocarbons and high propylene conversion. These results suggest that it should be possible to completely alkylate BTX, as conversion and selectivity of propylene for alkylation of each aromatic, both individually and in a mixture, was high.

\subsection{Extracting BTX from ALP Using Sulfolane}

Studies were performed of the conditions required to extract aromatic hydrocarbons out of the ALP generated during the cracking reactions to support process pathway 2 Fig. (2). The initial DOE set was based on a two-factor, three-level full factorial experimental design of: 1) solvent-to-solute ratio $(3: 1,5: 1$ and $7: 1)$ and 2) mixer temperature $\left(30,50\right.$, and $\left.70^{\circ} \mathrm{C}\right)$. The response measured was extraction yield. Four replicates were performed for a total of 36 runs.

The results are shown in Fig. (4). Increasing the temperature from 30 to $50^{\circ} \mathrm{C}$ resulted in a significant increase in extraction yield. However, increasing the temperature from 50 to $70^{\circ} \mathrm{C}$ did not significantly improve the yield. Therefore, $50^{\circ} \mathrm{C}$ was chosen as the approximate optimum temperature.

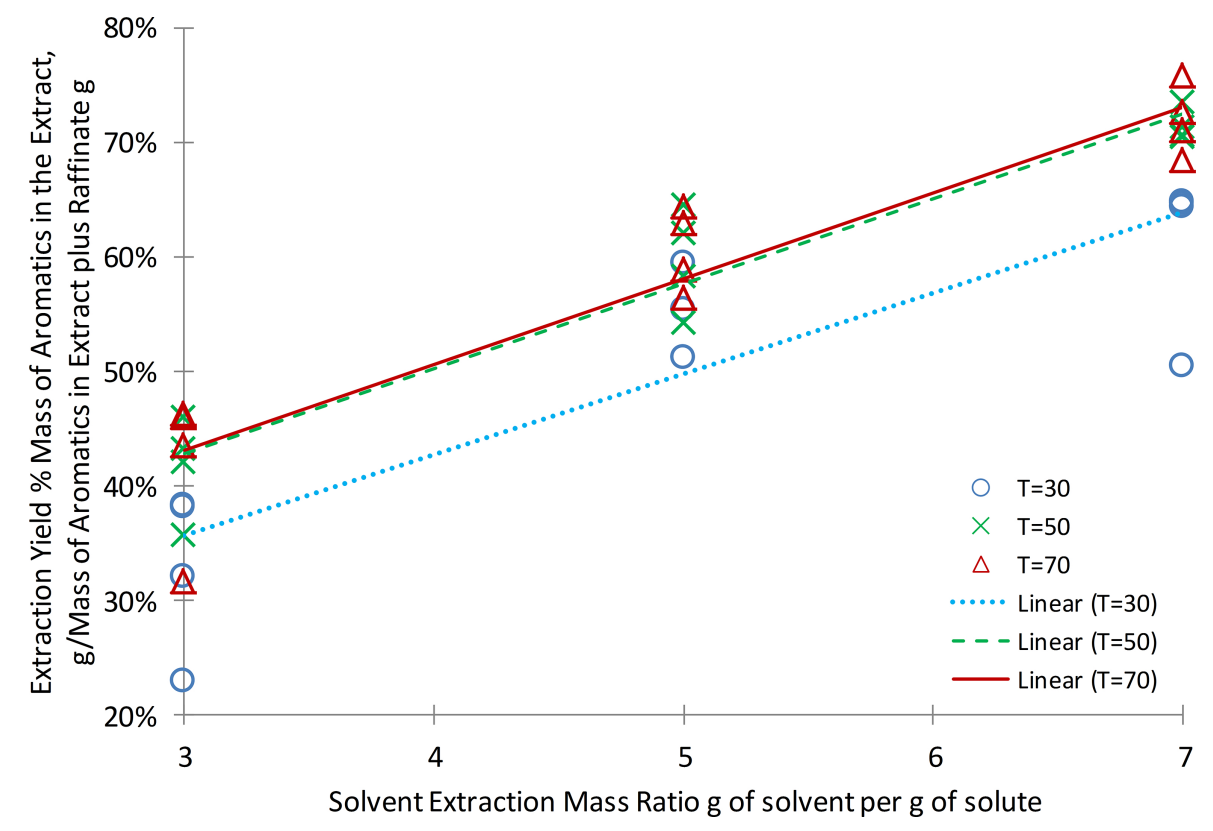

Fig. (4). The extraction yield of BTX into sulfolane as a function of temperature and solvent-to-BTX ratio.

Because the extraction yield was greatest at the higher solvent-to-BTX ratio utilized in the DOE, a parametric study was then performed with solvent-to-BTX ratios of 8:1, 9:1, 9.5:1, 10:1, 10.5:1, and 11:1 at an extraction temperature of $50^{\circ} \mathrm{C}$ to predict the saturation point. Fig. (5) shows the extraction yield as a function of solvent-to-BTX ratio. As shown, 
saturation is reached when the solvent-to-BTX ratio approaches 9:1 with no further significant improvement at higher ratios. Therefore a value of 9:1 was used in the simulations described below to generate the process conditions for this portion of the process.

These results provide data for a single stage extraction with an optimum efficiency of around $70 \%$. For a commercially viable process, a recovery of greater than $99 \%$ would be desirable. This can be accomplished using a multi-stage extraction system. The single stage data were used to estimate the efficiency of a multiple stage extraction following the methods and assumptions described by Shuler and Kargi [56]. This method assumes that the distribution coefficient is constant, that there is no sulfolane in the raffinate phase, and there is nothing but BTX and sulfolane in the extract phase. With these assumptions, the number of stages required to achieve a $99.5 \%$ recovery of BTX was estimated to be three.

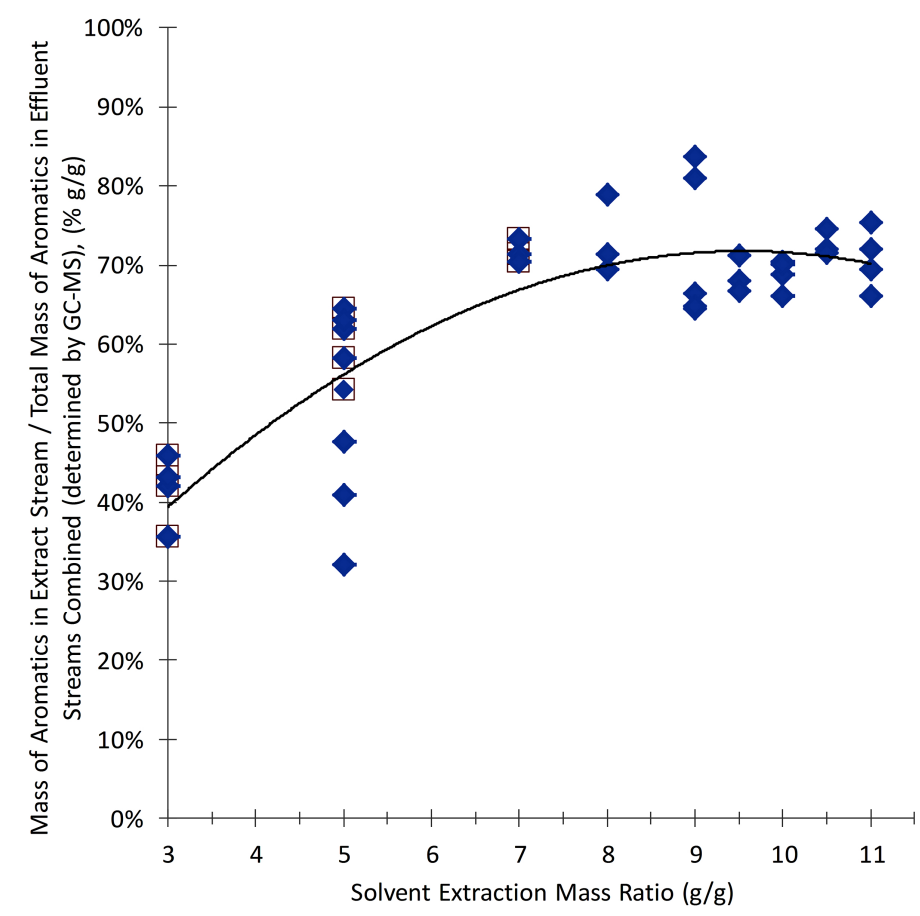

Fig. (5). The extraction yield of BTX into sulfolane as a function of solvent-to-BTX ratio.

\subsection{BTX Recovery and Purification}

Recovery of the BTX out of the sulfolane solvent and subsequent purification were studied using process simulation. Cumene was found to represent almost all of the roughly $0.12 \mathrm{wt} \%$ non-BTX aromatic hydrocarbons present in the sulfolane and thus it is assumed that all alkylated aromatic hydrocarbons recovered in the solvent were cumene. Assuming a sulfolane-to-BTX ratio of 9:1, the composition of the extract stream from the sulfolane extractor was estimated as shown in Table (4). This composition was used as the feed for the first distillation column.

Table 4. Estimated Aromatics-Rich Solvent Extractant Composition.

\begin{tabular}{|c|c|}
\hline Component & Concentration (wt\%) \\
\hline Water & trace \\
\hline Sulfolane & $89.10 \%$ \\
\hline Benzene & $0.71 \%$ \\
\hline Toluene & $4.07 \%$ \\
\hline Ethylbenzene & $1.04 \%$ \\
\hline$p$-Xylene & $1.03 \%$ \\
\hline$o$-Xylene & $3.92 \%$ \\
\hline$m$-Xylene & trace \\
\hline Cumene & $0.12 \%$ \\
\hline
\end{tabular}


Three different configurations were modeled with the most efficient configuration shown in Fig. (2). In this scheme, the first column separates the aromatic hydrocarbons from the sulfolane, allowing the sulfolane to be recycled back to the extractor. In the second column benzene is recovered as the light key to a purity of $99.2 \%$. The third column separates toluene as the light key to a purity of $99.0 \%$, and the last column separates the $o$ - and $p$-xylenes from the $m$ xylene and ethylbenzene.

The key design parameters for the optimum simulated system are shown in Table (5). It should be noted that the separation of ethylbenzene from xylene is challenging in traditional distillation, requiring a very large number of separation stages and a high reflux ratio. Even with these rigorous conditions, it is not possible to recover all of the $m$ xylene. Most of the contaminants in the xylene stream are heavier aromatic hydrocarbons (mostly cumene) which cannot be practically separated from the xylene at this point in the process.

Table 5. Key Design parameters of the figure 1b 4-column configuration to recover and Purify BTX from sulfolane extract.

\begin{tabular}{|c|c|c|c|c|}
\hline Parameter & BTEX Recovery Column & Benzene Column & Toluene Column & Xylenes Column \\
\hline Number of Theoretical Stages & 13 & 33 & 24 & 190 \\
\hline 1st Feed Stage & 3 & 19 & 12 & 4 \\
\hline Approximate Average Column Pressure, bar & 1.41 & 1.34 & 1.51 & 2.34 \\
\hline Estimated Overhead Temperature, ${ }^{\circ} \mathrm{C}$ & 102 & 58 & 117 & 152 \\
\hline Estimated Bottoms Temperature, ${ }^{\circ} \mathrm{C}$ & 310 & 136 & 149 & 156 \\
\hline Estimated Reflux Ratio & 1.8 & 5.0 & 4.6 & 9.5 \\
\hline Product Purity (wt\%) & 99.1 & 99.2 & 99.0 & 98.0 \\
\hline
\end{tabular}

\subsection{AvGas Blend Formulations}

The key fuel properties from AvGas blend formulations based on the alkylated aromatic hydrocarbons generated during the study are shown in Table (6). Cumene, cymene, and dimethylisopropyl benzene were used in the theoretical blend (CCD) assuming that the same ratio of benzene, toluene, and xylenes were alkylated as were obtained experimentally from catalytically cracking the soybean oil and concentrating the reaction products, as described in section 2.3, to generate the ALP shown in Table 2 as Run 8. Under these conditions, a fuel with an octane number of 96.2 and with acceptable flash point, freeze point, and heat of combustion is projected.

To verify the accuracy of this theoretical result, the ALP from Table (6), Run 8 was alkylated. After alkylation, the product was distilled to separate out the unconverted reactants. The resulting alkylated ALP had an octane number that exceeded the limit of the analyzer $(99.5 \mathrm{ON})$, a flash point of $59.5^{\circ} \mathrm{C}$, and a freeze point below the lower limit of the analyzer $\left(<-75^{\circ} \mathrm{C}\right)$. The difference from the theoretical values may be due to the assumption of linear blending used in the theoretical calculations and/or due to trace quantities of BTX, ethylbenzene, or other hydrocarbons in the experimental mixture. The similarity of the experimental and theoretical results suggests that it is likely feasible to produce a high octane AvGas via a two stage cracking-alkylation pathway from fatty acid-based oils, such as soybean oil.

Table 6. Key Fuel properties for alkylated aromatic blends for avGas production.

\begin{tabular}{|c|c|c|c|c|}
\hline & $\begin{array}{c}\text { Composition } \\
(\mathbf{w t} \%)\end{array}$ & Octane Number & Flash Point $\left({ }^{\circ} \mathbf{C}\right)$ & Freeze Point $\left({ }^{\circ} \mathbf{C}\right)$ \\
\hline Cumene & 14 & 13.9 & 6.14 & -13.44 \\
\hline Cymene & 40 & 38.7 & 19.98 & -27.08 \\
\hline DMIPB & 46 & 43.5 & 29.90 & -34.50 \\
\hline TMB & 46 & 50.6 & 52.39 & 16.54 \\
\hline Total CCD & 100 & 96.2 & 56.02 & -20.16 \\
\hline Total CCT & 100 & 103.2 & 78.51 & -75.03 \\
\hline
\end{tabular}

$\mathrm{HoC}=$ heat of combustion

DMIPB = dimethlyisopropylbenzene

$\mathrm{TMB}=1,2,4$-trimethylbenzene

$\mathrm{CCD}=$ cumene, cymene, and DMIPB (CCD) in the ratio $4: 1: 1$

$\mathrm{CCT}=$ cumene, cymene, and TMB were mixed in a 1:1:4 ratio

To improve the octane number further, a second scenario was considered as shown in the final row of Table (6). In this case cumene, cymene, and 1,2,4-trimethylbenzene (TMB) were used to form a simulated blend (CCT), assuming the same ratios of benzene, toluene, and xylenes as used above. Previous studies [57] suggest that the alkylation of 
xylenes with methanol yielded TMB which has a reported octane number of 110 . Substituting the higher octane number TMB for DIMPD, which has a reported octane number of 95, increased the octane number of the fuel blend to 103.2 while maintaining the flash point and lower freeze point within the range of acceptable values for these types of fuels. This higher octane blend could be attractive for those cases where the fuel producer wants to blend in lower octane fuel compounds, such as linear alkanes, while still meeting the fuel specifications of 100LL AvGas.

\section{CONCLUSION}

Two technically viable process pathways were conceived and demonstrated for the production of high octane Avgas from TG oils. This demonstration was accomplished by a combination of lab-scale experiments and process simulation. In the simpler pathway, an aromatics rich stream is produced by catalytic cracking of TG oil. The BTX in this stream are then alkylated with propylene to generate an unleaded fuel with an octane number $>96$ that meets the key specifications of 100LL AvGas. Scale-up of this simple pathway is recommended.

However it is possible that BTX yields and therefore the final fuel properties may not correspond to those obtained under laboratory conditions. In this case, this study has shown that the extraction of the BTX from other cracking reaction compounds of similar volatility using sulfolane or an equivalent solvent should be viable. Optimum extraction yields from simple laboratory experiments were $50^{\circ} \mathrm{C}$ and a 9:1 solvent-to-BTX ratio. The recovered BTX can then be alkylated as a mixture or purified into separate aromatic product streams for individual alkylation. This pathway allows alkylation of xylene with methanol to increase the octane number of the fuel above 100. Further, this pathway allows more exact blending of the alkylated aromatic hydrocarbons to optimize fuel quality. Any surplus benzene, toluene, or xylenes produced during cracking can be purified and sold as a by-product(s) or converted into other desirable products.

\section{CONFLICT OF INTEREST}

The authors declare no conflict of interest, financial or otherwise.

\section{ACKNOWLEDGEMENTS}

Funding for this work was received from the North Dakota Department of Commerce Centers of Excellence program via the Federal Aviation Administration's Air Transportation Center of Excellence for General Aviation Research (CGAR) Cooperative Agreement No. 04-C-GA-ERAU, the SUNRISE BioProducts Center of Excellence, and Bayer Crop Science.

\section{REFERENCES}

[1] Atwood, D. Full-scale engine detonation and power performance evaluation of swift enterprises 702 fuel, Final report, 2009. DOT/FAA/AR-08/53.

[2] EPI, Inc.. The Need for Leaded AvGas http://www.epi-eng.com/aircraft_engine_products/demise_of_AvGas.htm, 2010.

[3] Bruno, T.; Lovestead, T.; Windom, B. Application of the advanced distillation curve method to the development of unleaded aviation gasoline. Energy Fuels, 2010, 24, 3275-3284. [http://dx.doi.org/10.1021/ef100178e]

[4] Helder, D.; Behnken, J.; Aulich, T. Design of ethanol based fuels for aviation; SAE Technical Papers, 2000. [http://dx.doi.org/10.4271/2000-01-1712]

[5] Idem, R.; Katikaneni, S.; Bakhshi, N. Catalytic conversion of canola oil to fuels and chemicals: roles of catalyst acidity, basicity and shape selectivity on product distribution. Fuel Process. Technol., 1997, 51, 101-125. [http://dx.doi.org/10.1016/S0378-3820(96)01085-5]

[6] Katikaneni, S.; Adjaye, J.; Bakshi, N. Catalytic conversion of canola oil to fuels and chemicals over various cracking catalysts. Can. J. Chem. Eng., 1995, 73, 484-497.

[http://dx.doi.org/10.1002/cjce.5450730408]

[7] Adjaye, J.; Bakhshi, N. Upgrading of a wood-derived oil over various catalysts. Biomass Bioenergy, 1994, 7, $201-211$. [http://dx.doi.org/10.1016/0961-9534(94)00060-7]

[8] Prasad, Y.; Bakhshi, N. Effect of pretreatment of HZSM-5 catalyst on its performance in canola oil upgrading. Appl. Catal., 1985, 18, 71-85. [http://dx.doi.org/10.1016/S0166-9834(00)80300-0]

[9] Ooi, Y.; Zakaria, R.; Mohamed, A.; Bhatia, S. Catalytic conversion of palm oil-based fatty acid mixture to liquid fuel. Biomass Bioenergy, 2004, 27, 477-484.

[http://dx.doi.org/10.1016/j.biombioe.2004.03.003] 
[10] Chew, T.L.; Bhatia, S. Catalytic processes towards the production of biofuels in a palm oil and oil palm biomass-based biorefinery. Bioresour. Technol., 2008, 99(17), 7911-7922. [http://dx.doi.org/10.1016/j.biortech.2008.03.009] [PMID: 18434141]

[11] Tamunaidu, P.; Bhatia, S. Catalytic cracking of palm oil for the production of biofuels: Optimization studies. Bioresour. Technol., 2007, 98(18), 3593-3601. [http://dx.doi.org/10.1016/j.biortech.2006.11.028] [PMID: 17208441]

[12] Twaiq, F.; Mohamed, A.; Bhatia, S. Performance of composite catalysts in palm oil cracking for the production of liquid fuels and chemicals. Fuel Process. Technol., 2004, 85, 1283-1300. [http://dx.doi.org/10.1016/j.fuproc.2003.08.003]

[13] Twaiq, F.; Zabidi, N.; Bhatia, S. Catalytic conversion of palm oil to hydrocarbons: performance of various zeolite catalysts. Ind. Eng. Chem. Res., 1999, 38, 3230-3237. [http://dx.doi.org/10.1021/ie980758f]

[14] Bertero, M.; Sedran, U. Immediate catalytic upgrading of soybean shell bio-oil. Energy, 2016, 94, $171-179$.

[15] Han, M.; Lin, S.; Roduner, E. Study on the alkylation of benzene with propylene over H[beta] zeolite. Appl. Catal. A Gen., 2003, 243, $175-184$.

[http://dx.doi.org/10.1016/S0926-860X(02)00565-3]

[16] Perego, C.; Ingallina, P. Recent advances in the industrial alkylation of aromatics: new catalysts and new processes. Catal. Today, 2002, 73, $3-22$. [http://dx.doi.org/10.1016/S0920-5861(01)00511-9]

[17] Tian, Z.; Qin, Z.; Wang, G.; Dong, M.; Wang, J. Alkylation of benzene with propene over Hbeta zeolites near supercritical conditions. J. Supercrit. Fluids, 2008, 44, 325-330. [http://dx.doi.org/10.1016/j.supflu.2007.09.003]

[18] Lei, Z.; Yang, J.; Gao, J.; Chen, B.; Li, C. Gas-liquid and gas-liquid-solid reactors for the alkylation of benzene with propylene. Chem. Eng. Sci., 2007, 62, 7320-7326. [http://dx.doi.org/10.1016/j.ces.2007.08.043]

[19] Lei, Z.; Li, C.; Li, J.; Chen, B. Suspension catalytic distillation of simultaneous alkylation and transalkylation for producing cumene. Separ. Purif. Tech., 2004, 34, 265-271. [http://dx.doi.org/10.1016/S1383-5866(03)00199-0]

[20] Bellussi, G.; Pazzuconi, G.; Perego, C.; Girotti, G.; Terzoni, G. Liquid-phase alkylation of benzene with light olefins catalyzed by [beta]zeolites. J. Catal., 1995, 157, 227-234.

[http://dx.doi.org/10.1006/jcat.1995.1283]

[21] Perego, C.; Amarilli, S.; Millini, R.; Bellussi, G.; Girotti, G.; Terzoni, G. Experimental and computational study of beta, ZSM-12, Y, mordenite and ERB-1 in cumene synthesis. Microporous Mater., 1996, 6, 395-404. [http://dx.doi.org/10.1016/0927-6513(96)00037-5]

[22] Firnhaber, B.; Emmrich, G.; Ennenbach, F.; Ranke, U. Separation processes for the recovery of pure aromatics. Erdol. Erdgas. Kohle., 2000, $116,254-260$.

[23] Lee, F.; Coombs, D. Two-liquid-phase extractive distillation for aromatics recovery. Ind. Eng. Chem. Res., 1987, 26, 564-573. [http://dx.doi.org/10.1021/ie00063a024]

[24] Meindersma, G.; Podt, A.; De Haan, A. Selection of ionic liquids for the extraction of aromatic hydrocarbons from aromatic/aliphatic mixtures. Fuel Process. Technol., 2005, 87, 59-70. [http://dx.doi.org/10.1016/j.fuproc.2005.06.002]

[25] Hamid, S.; Ali, M. Comparative study of solvents for the extraction of aromatics from naphtha. Energy Sources, 1996, $18,65-84$. [http://dx.doi.org/10.1080/00908319608908748]

[26] Canales, R.; Brennecke, J. Comparison of ionic liquids to conventional organic solvents for extraction of aromatics from aliphatics. J. Chem. Eng. Data, 2016, 61, 1685-1699. [http://dx.doi.org/10.1021/acs.jced.6b00077]

[27] Mohsen-Nia, M.; Doulabi, F. Liquid-liquid equilibria for mixtures of (ethylene carbonate + aromatic hydrocarbon + cyclohexane). Thermochim. Acta, 2006, 445, 82-85. [http://dx.doi.org/10.1016/j.tca.2006.03.012]

[28] Huang, X.; Xia, S.; Ma, P.; Song, S.; Ma, B. Vapor-liquid equilibrium of N-formylmorpholine with toluene and xylene at $101.33 \mathrm{kPa}$. J. Chem. Eng. Data, 2008, 53, 252-255. [http://dx.doi.org/10.1021/je7005665]

[29] Mohsen-Nia, M.; Doulabi, F.; Manousiouthakis, V. Liquid + liquid) equilibria for ternary mixtures of (ethylene glycol + toluene + noctane). $J$. Chem. Thermodyn., 2008, 40, 1269-1273. [http://dx.doi.org/10.1016/j.jct.2008.03.014]

[30] García, J.; Fernández, A.; Torrecilla, J.; Oliet, M.; Rodríguez, F. Liquid-liquid equilibria for \{hexane + benzene + 1-ethyl-3methylimidazolium ethylsulfate $\}$ at $(298.2,313.2$ and 328.2)K. Fluid. Phase. Equilib., 2009, 282, $117-120$. 
[http://dx.doi.org/10.1016/j.fluid.2009.05.006]

[31] Pereiro, A.; Rodriguez, A. Application of the ionic liquid ammoeng 102 for aromatic/aliphatic hydrocarbon separation. J. Chem. Thermodyn., 2009, 41, 951-956.

[http://dx.doi.org/10.1016/j.jct.2009.03.011]

[32] ASTM D5134-98 Standard Test Method for Detailed Analysis of Petroleum Naphthas through n-Nonane by Capillary Gas Chromatography; ASTM International:: West Conshohocken, PA, 2008.

[33] ASTM D5307-97 Standard Test Method for Determination of Boiling Range Distribution of Crude Petroleum by Gas Chromatography; ASTM International:: West Conshohocken, PA, 2007.

[34] Fegade, S.; Tande, B.; Cho, H.; Seames, W.; Sakodynskaya, I.; Muggli, D.; Kozliak, E. Aromatization of propylene over HZSM-5: a design of experiments a DOE Approach. Chem. Eng. Commun., 2013, 200, 1039-1056. [http://dx.doi.org/10.1080/00986445.2012.737385]

[35] Seames, W.; Luo, Y.; Ahmed, I.; Aulich, T.; Kubátová, A.; Štávová, J.; Kozliak, E. The thermal cracking of canola and soybean methyl esters: improvement of cold flow properties. Biomass Bioenergy, 2010, 34, 939-946. [http://dx.doi.org/10.1016/j.biombioe.2010.02.001]

[36] Št’ávová, J.; Beránek, J.; Nelson, E.P.; Diep, B.A.; Kubátová, A. Limits of detection for the determination of mono- and dicarboxylic acids using gas and liquid chromatographic methods coupled with mass spectrometry. J. Chromatogr. B Analyt. Technol. Biomed. Life Sci., 2011, 879(17-18), 1429-1438.

[http://dx.doi.org/10.1016/j.jchromb.2010.11.027] [PMID: 21185238]

[37] Stávová, J.; Stahl, D.C.; Seames, W.S.; Kubátová, A. Method development for the characterization of biofuel intermediate products using gas chromatography with simultaneous mass spectrometric and flame ionization detections. J. Chromatogr. A, 2012, 1224, 79-88. [http://dx.doi.org/10.1016/j.chroma.2011.12.013] [PMID: 22245174]

[38] ASTM D1655-11b Standard Specification for Aviation Turbine Fuels; ASTM International:: West Conshohocken, PA, 2011.

[39] ASTM D1298-99 Standard Test Method for Density, Relative Density (Specific Gravity), or API Gravity of Crude Petroleum and Liquid Petroleum Products by Hydrometer Method; ASTM International:: West Conshohocken, PA, 2003.

[40] ASTM D974-11 Standard Test Method for Acid and Base Number by Color-Indicator Titration; ASTM International:: West Conshohocken, PA, 2011.

[41] ASTM D5972-05 Standard Test Method for Freezing Point of Aviation Fuels (Automatic Phase Transition Method). ; ASTM International:: West Conshohocken, PA, 2005.

[42] ASTM D3828-05 Standard Test Methods for Flash Point by Small Scale Closed Cup Tester. ; ASTM International:: West Conshohocken, PA, 2005.

[43] ASTM D4809-00 Standard Test Method for Heat of Combustion of Liquid Hydrocarbon Fuels by Bomb Calorimeter (Precision Method); ASTM International:: West Conshohocken, PA, 2005.

[44] ASTM D86-11a Standard Test Method for Distillation of Petroleum Products at Atmospheric Pressure. ; ASTM International:: West Conshohocken, PA, 2011.

[45] ASTM D1319-10 Standard Test Method for Hydrocarbon Types in Liquid Petroleum Products by Fluorescent Indicator Adsorption; ASTM International:: West Conshohocken, PA, 2010.

[46] Abrams, D.; Prausnitz, J. Statistical thermodynamics of liquid mixtures: A new expression for the excess Gibbs energy of partly or completely miscible systems. AIChE J., 1975, 21, 116-128. [http://dx.doi.org/10.1002/aic.690210115]

[47] Huang, X.; Xia, S.; Ma, P.; Song, S.; Ma, B. Vapor-liquid equilibrium of N-formylmorpholine with toluene and xylene at 101.33 kPa. J. Chem. Eng. Data, 2008, 53, 252-255. [http://dx.doi.org/10.1021/je7005665]

[48] Renon, H.; Prausnitz, J. Local compositions in thermodynamic excess functions for liquid mixtures. AIChE J., 1968, 14, $135-144$. [http://dx.doi.org/10.1002/aic.690140124]

[49] Lee, S.; Kim, H. Liquid-liquid equilibria for the ternary systems sulfolane + octane + benzene, sulfolane + octane + toluene, and sulfolane + octane + p-xylene at elevated temperatures. J. Chem. Eng. Data, 1998, 43, 358-361. [http://dx.doi.org/10.1021/je9702246]

[50] Lee, F.; Coombs, D. Two-liquid-phase extractive distillation for aromatics recovery. Ind. Eng. Chem. Res., 1987, 26, 564-573. [http://dx.doi.org/10.1021/ie00063a024]

[51] Ashour, L.; Abu-Eishah, S. Liquid-liquid equilibria of ternary and six component systems including cyclohexane, benzene, toluene, ethylbenzene, cumene, and sulfolane at 303.15K. J. Chem. Eng. Data, 2006, 51, 1717-1722. [http://dx.doi.org/10.1021/je060153n]

[52] American Petroleum Institute. Technical Data Book - Petroleum Refining; API, 1997, Vol. 1,

[53] Kadrmas, C.; Khambete, M.; Kubátová, A.; Kozliak, E.; Seames, W. Optimizing the production of renewable aromatics via crop oil catalytic cracking. Process, 2015, 3, 222-234. [http://dx.doi.org/10.3390/pr3020222] 
[54] Fegade, S.; Tande, B.; Kubátová, A.; Seames, W.; Kozliak, E. A novel two-step process for the production of renewable aromatic hydrocarbons from triacylglycerides. Ind. Eng. Chem. Res., 2016, 54, 9657-9665. [http://dx.doi.org/10.1021/acs.iecr.5b01932]

[55] Kubátová, A.; Št’ávová, J.; Seames, W.; Luo, Y.; Sadrameli, S.; Linnen, M.; Baglayeva, G.; Smoliakova, I.; Kozliak, E. Triacylglyceride thermal cracking: pathways to cyclic hydrocarbons. Energy Fuels, 2012, 26, 672-685. [http://dx.doi.org/10.1021/ef200953d]

[56] Shuler, M.; Kargi, F. Bioprocess Engineering: Basic Concepts, 2nd ed; Prentice Hall: Englewood Cliffs, NJ, 2011.

[57] Nishi, H.; Nowinska, K.; Moffat, J. The alkylation of toluene with methanol on microporous heteropoly oxometalates. J. Catal., 1989, 116, 480-487.

[http://dx.doi.org/10.1016/0021-9517(89)90114-0]

\section{(C) 2017 Seames et al.}

This is an open access article distributed under the terms of the Creative Commons Attribution 4.0 International Public License (CC-BY 4.0), a copy of which is available at: https://creativecommons.org/licenses/by/4.0/legalcode. This license permits unrestricted use, distribution, and reproduction in any medium, provided the original author and source are credited. 